\title{
A abordagem explícita da variação linguística e da concordância verbal em um livro didático ${ }^{1}$
}

\section{César Augusto González}

Universidade Federal do Rio Grande do Sul (URGS)

\begin{abstract}
Resumo
Atualmente, é exigência dos Parâmetros Curriculares Nacionais que se aborde a questão da variação linguística na sala de aula de língua materna. Essa exigência afeta também livros didáticos, que, selecionados, comprados e distribuídos para escolas públicas de todo o Brasil por meio do Programa Nacional do Livro para o Ensino Médio, trazem todos ao menos um capítulo sobre essa questão. Interessados em saber como é feita a abordagem da variação pelo livro didático, analisamos a coleção de ensino médio mais adotada no estado do Rio Grande do Sul com os objetivos de (1) descrever como a variação é explícitamente discutida em termos das noções de língua, norma e variedades linguísticas populares, e (2) investigar se a concordância verbal - fenômeno variável altamente estigmatizado - tem sua variabilidade discutida. Entende-se que tal discussão é necessária se quisermos combater o preconceito que se associa à concordância verbal variável.
\end{abstract}

Palavras-chave: Variação linguística, livro didático, concordância verbal.

\begin{abstract}
Currently, the National Curricular Parameters demand that linguistic variation be discussed in Portuguese classes. This determination also affects textbooks, which are selected, bought and distributed to public schools around the country through the National Program of Books for High School. All the books approved by the Program, therefore, include at least one chapter on the subject. With the aim of discovering how linguistic variation is discussed in these textbooks, we analyze the high school textbook most adopted in the state of Rio Grande do Sul, with the following objectives: (1) describing how linguistic variation is explicitly dealt with in terms of language, norm and popular linguistic varieties; and (2) examining whether verbal agreement - a highly stigmatized linguistic variable is discussed in terms of its variability. We understand that this discussion is necessary if we wish to counteract the prejudice associated with the variable of verbal agreement.
\end{abstract}

Key-words: Linguistic variation, textbooks, verbal agreement.

\section{INTRODUÇÃOO}

Recentemente assistimos na mídia um intenso debate a respeito do livro didático de Língua Portuguesa e Literatura (LPL) Por uma vida melhor, que abordava explicitamente a

1 Este trabalho se beneficiou da orientação do Prof. Dr. Paulo C. Guedes e da leitura atenta e crítica do Prof. Dr. Cléo V. Altenhofen e da Profa. Ma. Maitê Gil. A eles, meus mais sinceros agradecimentos. Desnecessário dizer que os pontos de vista expressos aqui são de minha inteira responsabilidade. 
questão da variação linguística ao tratar da concordância verbal. Ao contrário do que circulou na mídia, o livro didático não "ensinava a falar errado". O livro ensinava a norma culta a partir de variedades linguísticas populares. Ao fazer isso, ia ao encontro das exigências dos Parâmetros Curriculares Nacionais (PCN), que dizem explícitamente que

A variação é constitutiva das línguas humanas, ocorrendo em todos os níveis. Ela sempre existiu e sempre existirá, independentemente de qualquer ação normativa. Assim, quando se fala em "Língua Portuguesa" está se falando de uma unidade que se constitui de muitas variedades. (Brasil, 1998:29)

Os PCN inclusive listam entre os "Objetivos gerais de Língua Portuguesa” o seguinte: "conhecer e valorizar as diferentes variedades do Português, procurando combater o preconceito linguístico" (Brasil, 1998:33). Esse objetivo se reflete na exigência, por parte do Programa Nacional do Livro para o Ensino Médio (PNLEM), de que o livro didático aborde a questão da variação linguística e não veicule quaisquer preconceitos ${ }^{2}$. Por isso, neste trabalho, analisamos a coleção didática de LPL aprovada pelo PNLEM/2009 mais adotada no estado do Rio Grande do Sul, com o intuito de verificar

(i) como o livro didático aborda explicitamente a questão da variação linguística em seu capítulo dedicado ao tema; e

(ii) se o livro didático é coerente com seu capítulo sobre variação ao abordar fenômenos linguísticos altamente estigmatizados (especificamente, a concordância verbal), trazendo considerações sobre a variabilidade desses fenômenos.

O presente trabalho se organiza da seguinte forma: na seção seguinte, buscamos explicitar algumas contribuições que os estudos sobre a variação linguística trouxeram para o ensino de língua. Posteriormente, apresentamos a análise dos capítulos dedicados à variação linguística e à concordância verbal no livro didático Português: Linguagens, de Cereja \& Magalhães, livro mais adotado no estado de Rio Grande do Sul (RS), de acordo com a Secretaria de Educação do Estado. Encerramos o artigo com algumas considerações a

2 "Será excluída obra que [...] veicular preconceitos de origem, cor, condição econômico-social, etnia, gênero, orientação sexual, linguagem ou qualquer outra forma de discriminação." (Brasil, 2008:15 [grifo adicionado].) Ver também o Anexo do Catálogo do PNLEM/2009, que apresenta as fichas de avaliação das obras didáticas. Na ficha 3 - "Conhecimentos linguísticos" - encontram-se os seguintes itens:

b) A concepção de língua contempla sua natureza dinâmica e variável, como um sistema adaptável ao contexto sociocultural? c) A gramática é considerada um sistema de regras de funcionamento da língua, que toma forma nas diversas situações de uso? [...] e) A variação linguística é vista como um fenômeno próprio das línguas? (Brasil, 2008:131.) 
respeito das análises feitas.

\section{CONTRIBUIÇÕES DOS ESTUDOS DA VARIAÇÃO PARA O ENSINO DE LÍNGUA}

Neste trabalho, nos filiamos à tradição de estudos sociolinguísticos variacionistas iniciada por Labov em seu estudo sobre a centralização dos ditongos /ay/ e /aw/ na ilha de Martha's Vineyard. Estudos nesse quadro teórico questionam a homogeneidade do sistema linguístico postulada pela tradição de estudos sobre a linguagem que nasce com Saussure.

Labov (2008) nos lembra que a língua, tal como definida por Saussure, é um fato social, mas que a proposição de que ela "existe virtualmente em cada cérebro" (Saussure, 2006:21) foi interpretada como uma autorização para que se investigasse o conhecimento linguístico de qualquer indivíduo, inclusive, por vezes, o próprio linguista, já que todos teriam, em tese, o mesmo conhecimento linguístico. Por outro lado, a fala, identificada com o uso indivídual da língua, deveria ser estudada a partir dos usos linguísticos que faz o indivíduo. Nas palavras de Labov (2008:218): “Assim, temos o paradoxo saussureano: o aspecto social da língua é estudado pela observação de qualquer indivíduo, mas o aspecto individual somente pela observação da língua em seu contexto social”.

Além disso, posteriormente, com a eleição da competência linguística como objeto de estudo da linguística chomskiana (Chomsky, 1978), o enunciado empírico foi abandonado. A investigação se concentraria nas intuições do falante acerca da gramaticalidade e dos significados de frases construídas pelo linguista com o intuito de levantar hipóteses a respeito da estrutura linguística.

Labov (2008:220) nos lembra que, apesar do sucesso da investigação linguística tal como projetada pelas tradições saussureana e chomskiana,

\footnotetext{
é difícil evitar a conclusão sensata de que o objeto da linguística tem de ser, ao fim e ao cabo, o instrumento de comunicação usado pela comunidade de fala; e se não estivermos falando desta língua, há qualquer coisa de trivial em nosso procedimento.
}

Ou seja, para Labov, a eleição de objetos de estudo idealizados faz com que a linguística se distancie do fenômeno empírico que tenta explicar; por consequência, é importante que o linguista colete dados de fala e produza sua teoria a partir deles. Obviamente, tais dados são colhidos em uma comunidade de fala real, que é, naturalmente, heterogênea; em vista disso, a linguística deve desenvolver métodos capazes de enfrentar essa heterogeneidade e a variabilidade linguística que a evidencia. 
Para sustentar sua crítica, Labov (2008) busca refutar os principais argumentos contra o estudo da fala: (1) a agramaticalidade da fala cotidiana; (2) a existência de variação e estruturas heterogêneas; (3) o problema de gravar a fala em ambientes naturais; e (4) a raridade das formas gramaticais. Labov alega que (1) parece ser um mito: dados de suas pesquisas mostram que a grande maioria dos dados de fala são "bem formadas sob qualquer critério" (2008:237). Quanto a (2), a alegação laboviana é que a variação é a situação normal; além disso, a variação apresenta estratificação social e estilística regular mesmo com poucos informantes, o que significa que a fala não sofre efeitos de "variação livre", mas que a variação é condicionada por fatores linguísticos e extra-linguísticos mensuráveis. Sobre (3), Labov afirma que se trata de um problema de natureza técnica que vem se resolvendo com o advento de novas tecnologias capazes de gravar som com qualidade. Sobre (4), por fim, a raridade de determinadas formas gramaticais pode ser suprida por técnicas de entrevista que levem o informante a produzi-las em contexto; tais técnicas são dependentes das formas linguísticas investigadas e estão em constante desenvolvimento.

Os estudos labovianos passaram então a investigar as relações entre as estruturas sociais e estruturas linguísticas. Para isso, variáveis linguísticas são selecionadas com base em três critérios: (a) a variável deve ser frequente, para que seja posssível verificá-la a partir de entrevistas não estruturadas ou entrevistas curtas; (b) a variável deve ser estrutural, "quanto mais integrado o item estiver num sistema mais amplo de unidades funcionais, maior será o interesse linguístico intrínseco do nosso estudo" (Labov, 2008:26); e (c) a variável deve ser altamente estratificada, i.e. investigações preliminares devem sugerir uma distribuição distinta entre estratos ordenados da sociedade (faixa etária, classe social etc.).

Tomemos como exemplo o estudo sobre o /r/ em final de sílaba no inglês novaiorquino (Labov, 2008). Para fazer seu estudo, Labov visitou três grandes lojas de departamentos de Nova York. Em cada loja, pedia que os atendentes lhe informassem a localização de uma seção específica, que ele sabia se encontrar no quarto andar (fourth floor ) do prédio. Foram analisadas duas possíveis variantes: presença da constrição consonantal (a variante de prestígio) ou ausência da constrição consonantal (a variante estigmatizada). Todas as respostas foram anotadas imediatamente após a audição e posteriormente procedeu-se a uma análise estatística dos dados. A análise mostrou que nas lojas cujo público era a classe média e a classe média alta, os atendentes tendiam a usar a variante de prestígio; por outro lado, na loja cujo público era a classe operária, os atendentes tendiam a usar a variante estigmatizada. Labov (2008:72) conclui que "os grupos estão ordenados por seu uso diferenciado de (r-1) [presença de constrição consonantal] na mesma ordem de sua 
estratificação por fatores extralinguísticos".

O que essa análise mostra é que as variáveis linguísticas não são completamente livres; não se trata de uma escolha aleatória do falante. Pelo contrário: elas obedecem condicionamentos linguísticos e extralinguísticos. No estudo relatado, não importavam as manifestações de /r/ que não se encontrassem em um contexto linguístico bastante específico, o final de sílaba. Não interessavam, por exemplo, palavras como right ("certo"), thread ("fio") e arrive ("chegar"). Nelas, a variação que se buscava correlacionar com a estrutura social de classes não seria encontrada. Por outro lado, a variável linguística de fato emerge de diferentes formas na fala de diferentes classes sociais. Na verdade, a influência de uma série de categorias extralinguísticas pode ser averiguada por meio da investigação sociolinguística laboviana. No mesmo estudo, por exemplo, Labov buscou mapear os efeitos da origem étnica (negros tendem a usar a variante desprestigiada), da ocupação dos trabalhadores das lojas (chefes de seção e vendedores produzem a variante de prestígio muito mais frequentemente que os repositores) e da idade (grosso modo, os informantes mais jovens nas lojas de público mais abastado foram os que mais produziram a variante de prestígio).

Labov não abandona a noção de que o linguista estuda a língua. Entretanto, ele concebe a língua como o meio de comunicação de uma comunidade de fala. Uma vez que a comunidade de fala é sempre heterogênea, o sistema linguístico deve ser heterogêneo também. A sociolinguística laboviana dá conta dessa heterogeneidade postulando a existência de regras variáveis, que são condicionadas por elementos linguísticos e extralinguísticos.

\section{Três postulados para um ensino de LPL que atente para a variação linguística}

O que os estudos labovianos mostram é que a variação não ocorre livremente, mas é condicionada social e linguisticamente. Seus achados nos trazem evidências de que a variação é fenômeno constitutivo da língua. O sistema linguístico, portanto, comporta regras variáveis que compõem um quadro um tanto heterogêneo: a língua passa a ser vista como um conjunto de variedades que tendem a emergir de acordo com uma série de fatores extralinguísticos.

Dentro desse quadro teórico, podemos apontar pelo menos três postulados para um ensino de LPL que atente para a questão da variação linguística. Tal atenção, além de ser uma exigência por parte dos PCN, é necessária para o enfrentamento do preconceito linguístico e para a plena participação das diferentes variedades linguísticas que habitam a sala de aula. Tentaremos esboçar esses postulados a seguir: 
Postulado \# 1: A língua não é homogênea

Se de fato o sistema linguístico comporta regras variáveis - regras condicionadas social e linguisticamente - então não podemos acreditar que a língua seja homogênea. $\mathrm{Na}$ verdade, a língua é heterogênea: comporta em si uma série de possibilidades de dizer, uma série de variedades linguísticas, todas sistemáticas, todas gramaticais do ponto de vista linguístico.

Importante notar o adjetivo "gramaticais": ele está sendo usado para se referir àquilo que for produzido de acordo com as regras da língua (inclusive as variáveis), internalizadas por todos os falantes de uma língua. Ao contrário do que se poderia imaginar, não se está pensando aqui em certa tradição gramatical, que cuida de estabelecer um padrão linguístico homogêneo baseado nos cânones da literatura e que tem tradicionalmente balizado o ensino de língua materna no Brasil.

No nosso caso, a tradição gramatical se baseou nos cânones da literatura romântica portuguesa e, com isso, gerou um padrão extremamente artificial e anacrônico (Faraco, 2008). Daí que as regras de nossa tradição gramatical não são (nem poderiam ser) seguidas pelos falantes de português brasileiro - mesmo os mais cultos. Apesar disso, é o conhecimento dessa tradição gramatical que é habitualmente valorizado pela escola. Esse conhecimento é também utilizado como instrumento de discriminação e preconceito. Faraco chama a parcela da língua desenhada pela tradição gramatical de norma-padrão:

\footnotetext{
a norma-padrão - quando existe em uma determinada sociedade - é um construto idealizado (não é um "dialeto" ou um conjunto de "dialetos", como é a norma culta, mas uma codificação taxonômica de formas tomadas como um modelo linguístico ideal). (Faraco, 2008:174)
}

A norma-padrão, como vemos, não é falada por ninguém na nossa sociedade - daí sua homogeneidade, sua impossibilidade de variar. É o mito da homogeneidade da língua que sustenta afirmações preconceituosas. Somente se reconhecendo que a variação linguística é inerente a qualquer língua é que poderemos combater o preconceito de que se cobrem determinadas variedades linguísticas. 
Postulado \#2: As construções linguísticas não são certas ou erradas

Dizer que uma construção linguística é certa ou errada é desconhecer os achados dos estudos variacionistas, pois, se acreditamos que a língua é heterogênea, entenderemos que a língua que emerge da boca de um falante nativo nunca vai trazer construções erradas - todas as construções que ele produzirá serão gramaticais.

Um falante nativo de português brasileiro, por exemplo, nunca dirá que gosta de sair com amigos para beber "*cerveja uma", pois, em nossa língua, o artigo sempre precede o substantivo. Por outro lado, o mesmo falante pode dizer que andou lendo "uns livro muito bom", pois a regra de concordância nominal de número é uma regra variável no português brasileiro.

Os que falam em certo e errado na língua tomam por base a norma-padrão. Entretanto, como não há quem a fale e porque ela é comumente utilizada como instrumento de discriminação social, não há razão em pautar o ensino de LPL por ela. O ensino de língua materna deve se preocupar com a norma culta:

As variedades que ocorrem em usos mais monitorados da língua por segmentos sociais urbanos, posicionados do meio para cima na hierarquia econômica e, em consequência, com amplo acesso aos bens culturais, em especial à educação formal e à cultura escrita. (Faraco, 2008:173)

Porque a norma culta é um conjunto de variedades efetivamente utilizadas pelos falantes de português brasileiro, é importante que ela esteja na pauta do ensino de LPL. E porque ela é definida no plural, devemos entender que a norma culta também varia. A norma culta é o conjunto de fenômenos normais nos usos linguísticos dos falantes cultos. E não um conjunto de prescrições que visam a normatizar os usos da língua.

Melhor que assumir a dicotomia certo/errado seria entender que as formas linguísticas são mais ou menos adequadas a uma determinada situação de interlocução. É inadequado, por exemplo, escrever o presente artigo sem prestar atenção na concordância verbal ou nominal. E é igualmente inadequado fazer a concordância verbal e nominal de acordo com a normapadrão em todas as nossas intervenções na conversa sobre futebol com nossos amigos em um bar. Nesse sentido, pode-se dizer que as noções de certo/errado não nos ajudam a construir conhecimento sobre os usos da língua: não passam de instrumentos para a discriminação. Se pretendemos ensinar para a efetiva participação social, devemos expor nossos alunos a variadas situações de interlocução e discutir a adequação das formas linguísticas nelas 
empregadas.

Postulado \#3: Deve-se respeitar as diferentes variedades linguísticas

Observe-se que, ao sugerir que é a norma culta que deve orientar o ensino de LPL, não estamos sugerindo que as outras variedades linguísticas estejam banidas de sala de aula. Nem poderíamos: com a crescente democratização do acesso à escola, variedades linguísticas que antes não a visitavam hoje a habitam. O professor de LPL deve valorizar o conhecimento linguístico do aluno, mostrando que suas variedades linguísticas têm lugar na escola e em outras situações sociais. Do contrário, estará apenas reproduzindo o preconceito linguístico.

Devemos lembrar que a língua varia em diferentes eixos, inclusive intraindividualmente. Daí que possamos ensinar a norma culta sem ter que "apagar" as variedades linguísticas que o aluno conhece ao chegar à escola, pois o mais importante é que consigamos nos distanciar da instância de produção de nosso discurso para poder avaliar que variedade linguística é mais adequada àquela instância. Como dizem os PCNEM: "O desenvolvimento da competência linguística do aluno no Ensino Médio, [...] está pautado [...] principalmente, no saber utilizar a língua, em situações subjetivas e/ou objetivas que exijam graus de distanciamento e reflexão sobre contextos e estatutos de interlocutores." (Brasil, 2000:11)

Essa passagem sugere que, na sala de aula de LPL, o sociolinguístico deve preceder o linguístico. É isto que se tem chamado "pedagogia da variação linguística": mais importa ensinar a se movimentar adequadamente pelo amplo espectro de variedades linguísticas disponíveis e a escolher a variedade linguística mais adequada às situações de interlocução, que ensinar aos alunos as estritas regras da norma-padrão.

\section{A VARIAÇÃO LINGUÍSTICA NO LIVRO DIDÁTICO}

A coleção didática de LPL aprovada pelo PNLEM/2009 mais adotada pelas escolas públicas de nível médio no RS é a coleção Português: Linguagens, de Cereja \& Magalhães. Como já apontamos, a análise da coleção objetiva (i) verificar como é abordada a variação linguística no capítulo que o livro dedica a esse tema e (ii) verificar se o livro aborda a variação de um fenômeno linguístico altamente estigmatizado: a concordância verbal.

Para atingir o objetivo (i), buscamos, por meio da leitura dos sumários dos três volumes que perfazem a coleção, os capítulos que explicitamente trabalham a questão da 
variação linguística. Encontramos apenas um capítulo: "Linguagem, comunicação e interação" - o primeiro capítulo da coleção. Procedemos, então, a sua leitura para identificar como o livro trabalha com as noções sociolinguísticas de língua, norma culta e variedades linguísticas populares, noções diretamente relacionadas aos postulados esboçados na seção anterior. As seguintes foram as perguntas que nortearam nossa leitura:

Quadro 1 - Noções sociolinguísticas investigadas e perguntas norteadoras

\begin{tabular}{|c|l|}
\hline $\begin{array}{c}\text { Noções } \\
\text { investigadas }\end{array}$ & \multicolumn{1}{c|}{ Perguntas norteadoras } \\
\hline Língua & $\begin{array}{l}\text { O livro apresenta a língua como um sistema homogêneo ou como um } \\
\text { conjunto de variedades? }\end{array}$ \\
\hline \multirow{2}{*}{ Norma culta } & O livro confunde norma culta e norma-padrão? \\
\cline { 2 - 2 } & O livro explica a importância de conhecer a norma culta? \\
\hline \multirow{2}{*}{$\begin{array}{c}\text { Variedades } \\
\text { linguísticas } \\
\text { populares }\end{array}$} & $\begin{array}{l}\text { O livro fala sobre sua existência e seu lugar social, demonstrando } \\
\text { respeito por elas? }\end{array}$ \\
\cline { 2 - 2 } & $\begin{array}{l}\text { O livro menciona o desprestígio das variedades linguísticas populares } \\
\text { atentando para a questão do preconceito linguístico? }\end{array}$ \\
\hline
\end{tabular}

Para atingir o objetivo (ii), buscamos, por meio da leitura do sumário dos três livros da coleção, capítulos que abordassem o fenômeno linguístico da concordância verbal. Escolhemos esse fenômeno, pois acreditamos que ele é um exemplo de fenômeno variável altamente estigmatizado (vide confusão causada pela frase "Nós pega o peixe", famosa por figurar no livro didático Por uma vida melhor).

\section{A abordagem explícita da variação linguística no livro didático}

Aqui apresentaremos nossa análise da abordagem explícita da variação linguística no livro didático por meio da análise das noções sociolinguísticas de língua, norma culta e variedades linguísticas populares. A análise leva em consideração as perguntas norteadoras apresentadas acima.

\section{Noção \#1: Língua}

Ao abordar o conceito de "língua", o livro didático faz uso da seguinte definição: "Língua é um código formado por signos (palavras) e leis combinatórias por meio do qual as 
pessoas se comunicam e interagem entre si." (Cereja \& Magalhães, 2005, v.1:15.) Se não entendermos "leis combinatórias" como "leis invariáveis", essa definição pode ser considerada adequada do ponto de vista da sociolinguística defendido aqui: não aborda explicitamente a questão da variação na língua, mas também não exclui o entendimento de que a língua varia. Somente mais adiante o texto aborda a questão da variação:

\begin{abstract}
Nem a língua nem a fala são imutáveis. A língua evolui, transformando-se historicamente. Por exemplo, algumas palavras perdem ou ganham fonemas (sons); outras deixam de ser utilizadas; novas palavras surgem, de acordo com as necessidades, entre elas os empréstimos de outras línguas com as quais a comunidade mantém contato. A fala também se modifica, conforme a história pessoal de cada indivíduo, com sua formação escolar e cultural, com as influências que recebe do grupo social a que pertence, com suas intenções, etc. (Cereja \& Magalhães, 2005, v.1:15.)
\end{abstract}

Esse parágrafo aborda, ainda que timidamente, a questão da variação linguística: do ponto de vista do sistema, se entende que a língua muda através da história; do ponto de vista da fala de um indivíduo, se entende que ela é influenciada por traços como história pessoal, escolaridade, pertencimento a um grupo social, etc.

Mais adiante no texto pergunta-se ao leitor se ele percebe que as pessoas falam de modos diferentes. A resposta que o texto oferece é que a língua varia de acordo com uma série de traços sociais. Definem-se, então, as "Variedades linguísticas [que] são as variações que uma língua apresenta, de acordo com as condições sociais, culturais, regionais e históricas em que é utilizada.” (Cereja \& Magalhães, 2005, v.1:16.)

Mais adiante esse mesmo texto informa ao leitor que "Há dois tipos básicos de variação linguística: os dialetos e os registros" (Cereja \& Magalhães, 2005, v.1:16). O livro desenvolve uma diferença entre os termos, relacionando, por um lado, dialetos a diferentes territórios, faixas etárias, sexos, grupos sociais ou momentos históricos; e, por outro lado, registros a variações no grau de formalidade da situação, modo de expressão (se oral ou escrito) e "com a sintonia entre os interlocutores" (Cereja \& Magalhães, 2005, v.1:17). Como exemplo de variação dialetal, o livro traz um poema de Xanana Gusmão, poeta timorense. Como exemplo de variação de registro, o livro apresenta gírias, exemplificadas com "gírias curiosas" de grafiteiros, jornalistas, funkeiros e surfistas. Outro exemplo de variação de registro apresentado pelo livro é uma tabela de diferenças entre as modalidades falada e escrita da língua adaptada de um livro de Ingedore $\mathrm{Koch}^{3}$.

De tudo que foi dito a respeito de língua, entende-se que a visão de língua que se

3 Koch, I. G. V. (1997). A inter-ação pela linguagem. São Paulo: Contexto. 
estabelece neste capítulo é uma composta por um conjunto de variedades. Apesar disso, não está claro o que se está entendendo por dialetos e registros - o exemplo de variação topológica parece associar dialeto a espaço, mas a explicação o associa a uma série de variáveis extra-linguísticas; por outro lado, a noção de registro confunde formalidade, modalidade escrita ou oral e gírias.

Além disso, parece extremamente importante o fato de que não está esclarecido que a língua varia no eixo social: diz-se que a língua varia de acordo com o grupo social ao qual pertencemos, mas os únicos exemplos de variação social são os das gírias e jargões, que dificilmente admitiríamos como uma "variedade linguística", pois gírias e jargões, apesar de compor variedades, não são variedades. A falta de clareza com relação a essa questão pode fazer parecer que não há diferenças entre os usos da língua de diferentes estratos sociais - o que é uma falsidade que esconde a origem do preconceito linguístico.

\section{Noção \#2: Norma culta}

É abordada da seguinte forma:

Entre as variedades da língua, existe uma que tem maior prestígio: a variedade padrão. Também conhecida como língua padrão e norma culta, essa variedade é utilizada na maior parte dos livros, jornais e revistas, em alguns programas de televisão, nos livros científicos e didáticos, e é ensinada na escola. As demais variedades linguísticas - como a regional, a gíria, o jargão de grupos ou profissões (a linguagem dos policiais, dos jogadores de futebol, dos metaleiros, dos surfistas, etc.) - são chamadas genericamente de variedades não padrão.

Variedade padrão, língua padrão ou norma culta é a variedade linguística de maior pretígio social. (Cereja \& Magalhães, 2005, v.1:16.)

Como podemos ver, há uma confusão entre norma culta e norma-padrão, pois o texto toma as expressões como sinônimas. Além disso, a definição de norma culta/norma-padrão se apresenta no singular: "variedade linguística de maior prestígio". O problema é que, como vimos acima, a própria norma culta é heterogênea.

A larga utilização da norma culta já é uma espécie de justificativa de seu ensino, porém, mais adiante, o texto explica que situações sociais mais formais exigem a norma culta. Como exemplos de situações formais que exigiriam a norma culta, o livro traz a entrevista de emprego, o requerimento, a carta a um jornal ou revista, a exposição pública e a redação de concurso. Cabe aqui uma crítica - nenhum dos exemplos dados pelo livro como contextos em que a norma culta é requisito básico está no horizonte dos alunos (talvez a única exceção seja a redação de concurso). Exemplos como uma carta de reivindicações para o diretor da escola, bilhetes que circulam entre a escola e a casa dos alunos, entre outros, são exemplos mais adequados, pois estão dentro do universo de textos que os alunos conhecem e 
manipulam.

Noção \#3: Variedades linguísticas populares

Só se mencionam as variedades linguísticas populares nestes termos:

Variedades não padrão ou língua não padrão são todas as variedades linguísticas diferentes da padrão. Apesar de haver muitos preconceitos sociais em relação a variedades não padrão, todas elas são válidas e têm valor nos grupos ou nas comunidades em que são usadas. (Cereja \& Magalhães, 2005, v.1:16.)

Apesar de se reservar às variedades populares um lugar social (“os grupos ou comunidades em que são usadas"), o leitor acaba ficando com uma sensação de que as variedades populares são minoritárias e estão distantes de sua realidade. A verdade, contudo, é que as variedades populares são muito mais presentes em nossa vida do que sugere o livro didático - por exemplo, elas estão em nossas próprias interações com nossos amigos e com nossa família.

Também não se pode dizer que o livro discuta o preconceito que recai sobre as variedades linguísticas populares. O livro não discute o porquê de serem as variedades populares "todas válidas", nem busca debater os motivos que as levam a ser estigmatizadas. O obscurantismo que recobre essa afirmação não ajuda no combate ao preconceito linguístico.

Chama atenção, porém, o seguinte quadro:

Figura 1 - Quadro "Escola: democratizando oportunidades” (Cereja \& Magalhães, 2005, v.1:16)

\section{Escola: democratizando oportunidades}

Alguma vez você já se sentiu inferiorizado pelo modo como fala? Se sim, saiba que esse sentimento é normal. Isso geralmente ocorre quando nosso interlocutor é uma pessoa mais instruída do que nós e, por isso, tem maior domínio da variedade padrão.

A escola, ao assumir o compromisso de ensinar a variedade padrão, não tem em vista eliminar a língua que o aluno traz de casa, mas prepará-lo para se comunicar com segurança e competência, independentemente de sua origem social. 
É importante que este quadro deixe claro que o compromisso da escola é ensinar a norma culta e que isso não significa "eliminar" a língua do aluno. Entretanto, no primeiro parágrafo do texto, parece que o livro quer se distanciar da questão do preconceito linguístico (aliás, tal expressão não é mencionada em lugar algum nesse capítulo). Dizer que "é normal" se sentir inferiorizado ao falar com alguém com maior domínio da norma culta banaliza o estigma conjurado sobre os falantes de variedades populares. Essa banalização parece operar no mesmo sentido em que opera a falta de clareza a respeito da variação linguística entre os estratos sociais: oculta as diferenças linguísticas entre falantes e, assim, finge não existir preconceito (linguístico) em nossa sociedade. De outra forma: afirmar que se sentir inferiorizado ao falar com alguém com maior domínio da norma culta "é normal" é sugerir que o preconceito (linguístico) "é normal”.

\section{A abordagem da concordância verbal pelo livro didático}

Uma vez que o livro didático analisado mostrou que entende que a língua varia, ainda que não esteja claro em que sentido a língua varia, espera-se que, ao abordar fenômenos linguísticos altamente estigmatizados, o livro lembre seu leitor que aquele fenômeno é variável e que as diferentes variedades de português sempre obedecem a uma gramática. A coerência entre o discurso e a prática pedagógica, acreditamos, é um dos pontos de partida para o combate ao preconceito linguístico.

Primeiro, verificaremos o que os estudos variacionistas têm dito sobre a variabilidade da concordância verbal. Depois, descreveremos a abordagem dispensada aos mesmos fenômenos pelos livros didáticos. Com isso, verificaremos se o livro analisado é coerente.

A concordância verbal no português brasileiro

A concordância verbal é definida por Castilho (2010, p.411) como "a conformidade morfológica entre uma classe (neste caso, o verbo) e seu escopo (neste caso, o sujeito)." Tal conformidade implica que as formas do sujeito e do verbo de um enunciado sejam redundantes, como no exemplo dado por Castilho (2010:411): “(54) As portas da cidade caíram ante o ímpeto das tropas invasoras."

Sabemos que a concordância verbal é tida como "bom uso da língua" e que as 
variedades cultas do português brasileiro tendem a fazer sujeito e verbo concordar; entretanto, nenhum falante de português realiza a concordância verbal em todos os seus usos linguísticos, mesmo em textos mais monitorados. Bagno (2011) traz exemplos em que a concordância "falha" em textos escritos altamente monitorados, que vão desde textos jornalísticos, passando por autores consagrados da língua portuguesa (como Camões e Pe. Vieira), até obras científicas da área de estudos da linguagem. Em grande parte dos dados, ou a ordem entre os elementos é verbo - sujeito, ou há muito material linguístico entre sujeito e verbo.

Frente a isso, Bagno (2011:650) sugere que

A concordância "errada" só desperta rejeição e condenação quando

(i) sujeito e verbo estão na ordem SV e

(ii) não há grande quantidade de material fonético ou de segmentos escritos entre $\mathrm{S}$ e V. Por isso, a concordância do tipo eles chegou, na fala ou na escrita, provoca reação imediata dos falantes mais letrados (que se queixam que ela "dói no ouvido").

Fora dessas duas situações, porém, a concordância "errada" passa tranquilamente pelos ouvidos e sob os olhos desses mesmos falantes que, é claro, também se servem dela, como mostram tão bem os exemplos citados.

Castilho (2010) mostra também que, ao contrário do prescrito pela tradição gramatical, a concordância não se dá somente entre o verbo e seu sujeito, mas também entre o verbo e um adjunto adnominal ("O aumento desses crimes estão provocando situações irreversíveis") e entre o verbo e seu complemento ("Morador do bairro há muitos anos compraram cestas de alimento para os flagelados"). $\mathrm{O}$ autor sistematiza os principais fatores que condicionam a variação da concordância verbal:

1) Saliência morfológica: formas mais salientes morfologicamente acarretam mais casos de concordância. Assim, é mais fácil concordarmos "eles são" (verbo cuja forma singular é bastante diferente dessa forma verbal), que concordarmos "eles cantam" (verbo cuja forma singular é muito parecida com essa forma verbal, sendo a única diferença entre as duas a nasalidade final).

2) Proximidade/Distância entre o verbo e o sujeito: verbos adjacentes aos sujeitos provocam mais casos de concordância que verbos que se distanciam de seus sujeitos.

3) Posição do sujeito na sentença: o sujeito anteposto ao verbo favorece a concordância, o sujeito posposto, desfavorece.

4) Paralelismo linguístico: nas palavras de Castilho (2010:413) 
a presença da marca de plural favorece a concordância, ao passo que a ausência de uma marca precedente favorece a falta de concordância. [...] (61) a) Eles ficavam lá os dois, mas nunca se falaru assim. [...] (62) b) Tem outros que fala demais e num diz nada que se aproveite.

5) Nível sociocultural dos falantes: falantes de nível sociocultural mais alto tendem a fazer mais concordância que falantes de nível sociocultural mais baixos. Entretanto,

Pode-se reconhecer que as regras de concordância são variáveis tanto entre os brasileiros cultos quanto entre os brasileiros não escolarizados. O que distingue essas classes é a seleção do fator determinante da regra. Assim, para os primeiros, os fatores 2 e 3 são decisivos e, para os seguintes, os fatores 1 e 4. (Castilho, 2010, p.413)

O que Castilho afirma aqui vai ao encontro do proposto por Bagno sobre a rejeição da concordância "errada": os mais cultos parecem ser mais suscetíveis a fazer concordância quando o sujeito está antes do verbo e quando não há muito material linguístico entre ambos, por isso mesmo, quando a concordância "falha" nesses contextos linguísticos, eles percebem.

Talvez, então, seja produtivo, mostrar ao aluno que a concordância varia e que a ordem verbo-sujeito, assim como uma grande distância entre sujeito e verbo, podem nos levar a não fazer a concordância. Esse tipo de informação poderia, em tese, ajudar o aluno a monitorar seus usos de língua no momento em que produz textos que demandam a norma culta. Por outro lado, falar sobre os condicionantes linguísticos da variação da concordância verbal ajuda a mostrar a sistematicidade do fenômeno e, assim, mostra que todas as variedades linguísticas obedecem regras.

\section{Concordância verbal no livro didático}

Identificou-se, por meio da leitura do sumário da coleção didática analisada, a existência de apenas um capítulo dedicado ao tema da concordância verbal - o vigésimo terceiro capítulo do terceiro volume da coleção. Assim, nossa análise se restringe a apenas um capítulo da coleção dedicado à reflexão linguística e não tem pretensão de ser generalizante.

$\mathrm{Na}$ abertura do capítulo, o livro faz uso de um texto como pretexto para questionar o conhecimento linguístico do aluno. É a partir desse questionamento que o livro define concordância como "um princípio linguístico que orienta a combinação das palavras na frase" (Cereja \& Magalhães, 2005, v.3:230). Para abordar a concordância verbal, o livro questiona o aluno qual das seguintes frases observa as regras de concordância da norma-padrão: "O grupo de estudantes pedia bis ao cantor" ou "O grupo de estudantes pediam bis ao cantor". Depois 
de explicar que ambas as formas são aceitas, o livro afirma:

$\mathrm{O}$ fato de haver, às vezes, mais de uma possibilidade de concordar o verbo com o sujeito pode acarretar algumas dificuldades e, embora existam algumas regras sistematizadas, o aprendizado da concordância verbal depende em grande parte do uso sistematizado da língua, de nossa intuição linguística e, em caso de dúvida, de consultas constantes em gramáticas especializadas no assunto. (Cereja \& Magalhães, 2005, v.3:230.)

Esse parágrafo anuncia que "concordância é difícil”, "cheia de regras e exceções" muito parecido com o que o senso comum diz sobre o português. Nesse sentido, o livro didático está ajudando a difundir a ideia de que o conhecimento gramatical é para uns poucos instruídos. Na verdade, os seis quadros que abrigam as 26 regras e exceções de concordância apresentados pelo capítulo influenciam diretamente o imaginário de que "brasileiro não sabe português" - também pudera, que brasileiro sabe essas regras todas? - A grande maioria dos exercícios pede apenas que os alunos apliquem as regras de concordância listadas nos quadros de regras sobre frases completamente descontextualizadas. Interessante perceber que as frases dos exemplos dados nos quadros são extremamente parecidas com as dos exercícios. Se trata da mais mecânica aplicação de regras.

Há um único conjunto de exercícios que busca mostrar a relação da concordância verbal com o texto. Contudo, o texto selecionado é uma canção de Arnaldo Antunes que depende diretamente da variação na concordância para construir os sentidos que visa: esses exercícios acabam associando a variação da concordância com textos literários - textos aos quais a tradição gramatical permite a transgressão. A questão da variação da concordância verbal - se de fato quisermos abordar esse assunto de uma maneira séria - não pode ser abordorda a partir de um texto literário apenas. Fazer isso é fazer o mesmo que a tradição gramatical: arranjar explicações para os "desvios" dos literatos, abonando seus usos da língua, e condenar os usos dos usuários comuns, acusando-os de “erro". Vejamos: 
Figura 2 - Exercícios “A concordância na construção do texto” (Cereja \& Magalhães, 2005, v.3, p.237-238)

\section{A concordância na construção do texto}

Leia a letra de uma canção de Arnaldo Antunes e responda às questões propostas.

\section{fora de si}
eu fico louco
eu fico fora de si
eu fica assim
eu fica fora de mim
eu fico um pouco
depois eu saio daqui
eu vai embora
eu fica fora de si

eu fico oco

eu fica bem assim

eu fico sem ninguém em mim

(Ninguém. Ariola Discos, 1995.)

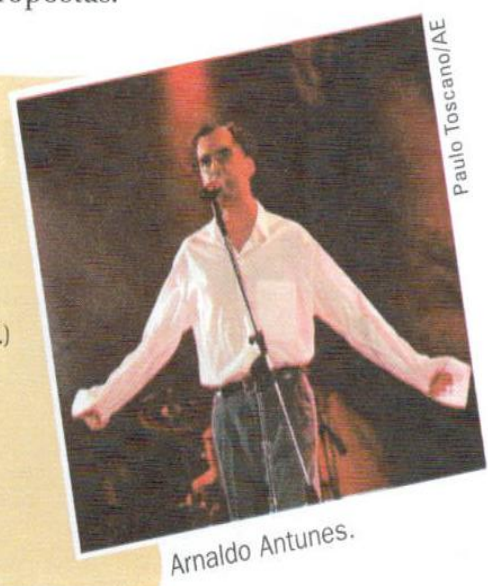

1. O poema é relativamente simples quanto ao conteúdo, já que se organiza em torno de uma idéia central. Qual
é essa idéia?

2. A canção se intitula "fora de si".

a) $\mathrm{O}$ que significam expressões como "ficar fora de si" ou "ficar fora de mim"?

b) Logo, o título da canção é coerente com seu assunto central?

3. 0 texto causa estranhamento devido à falta de concordância entre algumas palavras e termos.

a) Reescreva todos os versos em que se verificam desvios de concordância em relação ao padrão culto da língua, adequando-os a esse padrão.

b) Identifique o tipo de problema de concordância verificado em cada um dos versos reescritos: concordância verbal (entre o verbo e o sujeito), concordância nominal (entre os pronomes) ou concordância verba e nominal (entre o verbo e o sujeito e entre os pronomes),

4. Como se nota, os desvios do padrão culto identificados nessa canção são intencionais, uma vez que quebram pressupostos básicos do uso corrente da língua, dominados até por falantes não letrados, como, por exemplo, em "eu fica assim". Levando em conta que a forma de um texto geralmente está relacionada com seu conteúdo, responda: Que papel tem a concordância ou a falta dela na construção do sentido global da canção?

5. Em todos os versos, o centro do discurso é a figura do eu lírico, identificado pelo pronome reto eu. Apesar disso, os verbos e pronomes se alternam entre a 1: e a 3a pessoa, sugerindo a presença de outra pessoa, talvez um interlocutor, não mencionada explicitamente no texto.

a) Quem poderia ser essa pessoa?

b) Levante hipóteses: Que relação pode haver entre a falta de concordância do texto e o relacionamento entre o eu lírico e essa pessoa? 
Encontra-se também um conjunto de exercícios que se dedicam a reescrever cartuns e tiras utilizando as regras apontadas no capítulo como regras da "variedade padrão da língua". Um exercício assim, no entanto, acaba por descaracterizar o cartum e a tira, pois é característica linguística desses textos o uso de uma linguagem escrita com marcas explícitas de oralidade. Isso, novamente, faz do uso desses textos em sala de aula um pretexto para o ensino de regras de gramática.

Figura 3 - Exercício de reescrita de cartum (Cereja \& Magalhães, 2005, v.3, p. 239)

b) Leia agora a tira abaixo. Identifique nela uma ocorrência característica da linguagem falada e reescrevaa de acordo com a variedade padrão da língua.
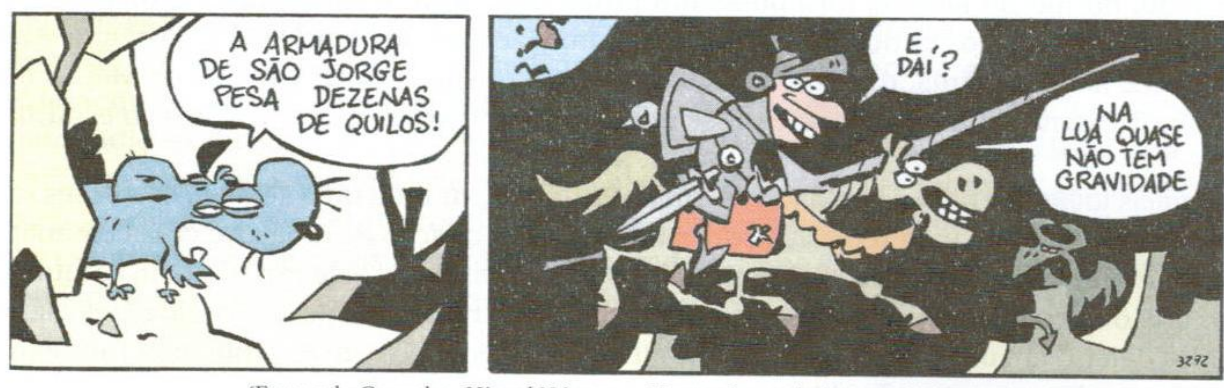

(Fernando Gonsales. Níquel Náusea - Nem tudo que balança cai!. São Paulo: Devir, 2003. p. 33.)

A variabilidade da concordância verbal só é mencionada na concordância do verbo com o sujeito composto posposto - caso em que é admitida pela tradição gramatical porque ocorre em grande quantidade nos textos de autores consagrados de língua portuguesa (Bagno, 2011). Contudo, como mostram os estudos linguísticos do português brasileiro, quando quer que o sujeito seja posposto ao verbo há uma tendência a não fazermos concordância, e isso não é sequer mencionado no livro didático.

Não há qualquer menção à variabilidade da concordância verbal no capítulo inteiro. Ou seja, o discurso de que a língua varia e de que devemos respeitar as variedades linguísticas, apresentado no primeiro capítulo do primeiro volume, foi esquecido na abordagem da concordância verbal. Na abordagem da concordância verbal, há apenas uma opção - a opção da tradição gramatical, a opção da língua homogênea e invariável. A mesma opção que promove o esterótipo da dificuldade de nossa língua materna e que instaura as condições para a propagação do preconceito linguístico. 


\section{CONSIDERAÇÕES FINAIS}

A discussão a respeito do livro didático para o ensino de jovens e adultos Por uma vida melhor revelou o grande preconceito linguístico existente em nossa sociedade. Entretanto, o que o livro faz é ensinar a norma culta da língua atentando para a variabilidade do fenômeno da concordância. Entendemos que esse é um dos caminhos para o enfrentamento do preconceito linguístico em nossa sociedade e, por isso, investigamos no livro didático de ensino médio aprovado pelo PNLEM/2009 mais adotado no estado do RS como é abordada a questão da variação linguística.

Com esse intuito, primeiramente, buscamos mostrar que a sociolinguística variacionista pode oferecer postulados úteis ao ensino de LPL. Esboçamos três postulados:

(1) a língua não é homogênea;

(2) as construções linguísticas não são certas ou erradas; e

(3) deve-se respeitar as diferentes variedades linguísticas.

Com base nesses postulados, apontamos três noções relevantes para a discussão a respeito da variação na sala de aula de LPL: língua, norma culta e variedades linguísticas populares.

Investigamos no livro didático selecionado como essas noções são abordadas e descobrimos que o livro mostra ao aluno que a língua varia, mas não o faz de uma maneira adequada, pois não aborda a questão da variação social e, ao abordar dialetos e registros, o faz de maneira confusa. Verificamos também que a norma culta é confundida pelo livro com a norma-padrão - confusão essa que se reflete no tratamento da concordância verbal: no capítulo dedicado ao tema, são listadas todas as regras prescritas pela tradição gramatical para a norma-padrão. Posteriormente, essas regras são exigidas em exercícios com frases descontextualizadas, o que contribui para ideia popular de que "português é difícil". Também descobrimos que o livro anuncia que as variedades linguísticas populares devem ser respeitadas, mas não é capaz de explicar por quê - o que dificulta o combate ao preconceito linguístico.

Espera-se que este texto contribua para o nosso conhecimento sobre o que tem chegado à escola em termos de variação linguística. Uma vez mapeados os conhecimentos sobre norma e variação que trazem os livros didáticos, poderemos discutir mais adequadamente alternativas de ensino que respeitem a variação linguística. 


\section{REFERÊNCIAS}

Bagno, M. A. (2011). Gramática Pedagógica do Português Brasileiro. São Paulo: Parábola.

Brasil. (1998). Secretaria de Educação Fundamental. Parâmetros Curriculares Nacionais: terceiro e quarto ciclos do ensino fundamental: língua portuguesa. Brasília: $\mathrm{MEC} / \mathrm{SEF}$.

Brasil. (2000). Secretaria de Educação Básica. Parâmetros Curriculares Nacionais para o Ensino Médio: Parte II - Linguagens, Códigos e suas Tecnologias. Brasília: $\mathrm{MEC} / \mathrm{SEB}$.

Brasil. (2008). Secretaria da Educação Básica; Fundo Nacional do Desenvolvimento da Educação. Língua Portuguesa: catálogo do Programa Nacional do Livro para o Ensino Médio: PNLEM/2009. Brasília: MEC/SEB.

Castilho, A. T. de. (2010). Nova Gramática do Português Brasileiro. São Paulo: Contexto.

Cereja, W. R. \& Magalhães, T. C. (2005). Português: Linguagens: volumes 1, 2 e 3: ensino médio. São Paulo: Atual.

Chomsky, N. (1978). Aspectos da teoria da sintaxe. In.: Saussure, F.; Jakobson, R.; Hjelmslev, L. T. \& Chomsky, N. Textos selecionados. São Paulo: Abril Cultural.

Faraco, C. A. (2008). Norma culta brasileira: desatando alguns nós. São Paulo: Parábola.

Labov, W. (2008). Padrões Sociolinguísticos.São Paulo: Parábola.

Saussure, F. (2006). Curso de Linguística Geral. São Paulo: Cultrix.

\section{O AUTOR}

César Augusto González é licenciado em Letras - Português/Inglês pela Universidade Federal do Rio Grande do Sul (UFRGS). É professor há seis anos, tendo sido professor de inglês em cursos livres e de português na rede pública de ensino. Atualmente cursa Mestrado em Linguística Aplicada pela UFRGS.

E-mail: cesaraugusto.gonzalez@gmail.com 